\title{
Study of the temperature effect on electrochemical impedance spectra in presence of an inhibitor
}

\author{
A. Popova, ${ }^{1 *}$ M. Christov, ${ }^{1}$ A. Vasilev $^{2}$ and Chr. Girginov ${ }^{1}$ \\ ${ }^{1}$ Department of Physical Chemistry, University of Chemical Technology and Metallurgy, \\ $8 \mathrm{Kl}$. Ohridski Blvd., 1756 Sofia, Bulgaria \\ ${ }^{2}$ Faculty of Chemistry, University of Sofia, $1 \mathrm{~J}$. Baucher Ave, 1126 Sofia, Bulgaria \\ *E-mail: apopova@uctm.edu
}

\begin{abstract}
The inhibitive properties of a quaternary ammonium salt displayed in case of mild steel corrosion in $1 \mathrm{M} \mathrm{HCl}$ are studied in the temperature range of $30-60^{\circ} \mathrm{C}$. Electrochemical impedance spectroscopy and polarization resistance method are applied. A structural model describing the processes at the interface is advanced and its parameters are estimated. The data on the temperature effect in inhibitor's presence and absence are juxtaposed. An interpretation of the results obtained is suggested.
\end{abstract}

Keywords: acid corrosion, inhibitors, EIS, mild steel.

Received: September 30, 2015. Published: November 4, 2015.

doi: $\underline{10.17675 / 2305-6894-2015-4-4-7}$

\section{Introduction}

The acid medium is often used in industry. Many industrial fields like oil and gas production, coverage deposition on metal surfaces through galvanization, enameling, painting, metallization, phosphatization, cold rolling, etc. require surfaces free from oxides and salts. The periodical scaling off and removal of corrosion products and/or deposits in power, chemical and metallurgical plants, sugar producing works, pipes, compressor stations and many other industrial appliances where deposits grow as a result of circulation of water and compounds specific for the process use an acid medium for periodical treatment. The corrosion protection in these fields is realized through inhibitors introduction. This illustrates the wide sphere of application and the resulting necessity of fabrication of new inhibitors effective in an acid medium [1-12]. These are almost always organic compounds of a varying molecular structure. Their effect is attributed to their adsorption as a result of the interaction of the polar centers of the organic molecule with the active centers on the metal surface which isolates them from further corrosion proceeding [13]. The polar centers of the inhibitor molecule contain heteroatoms like nitrogen, sulphur or oxygen, double and triple bonds, aromatic rings, etc. Thus the kinetics of cathodic hydrogen depolarization and anodic process of transfer of the basic metal ions to the corrosion medium changes in course of the proceeding electrochemical corrosion. 
In most of the cases the inhibitors act at comparatively low temperature values. This is, for an example, the case of etching which is a compulsory pretreatment of the metal surface prior to galvanic coverage deposition. The organic compounds displaying protective properties under ambient conditions change their behavior at elevated temperature values - some of them loose their protective properties, others preserve them, while there are inhibitors whose effectiveness even increases with temperature increase [4]. That is why it is of practical importance to know the temperature effect on the corrosion process of metal dissolution and the adsorption itself [5].

The quaternary ammonium salts attract definite interest as they are cation-active compounds [13-19] and are soluble in an acid medium where they show outlined protective properties.

The aim of the present investigation is to follow the inhibiting properties of the quaternary ammonium salt 3-methyl-2-phenylbenzo[d]thiazol-3-ium bromide (MPTB) as a function of the temperature in case of mild steel corrosion in $1 \mathrm{M} \mathrm{HCl}$. The structural formula is included in Table 1. The compound was synthesized to achieve the aim of the study. The temperature effect on the values of the electrochemical parameters characterizing the system is investigated through juxtaposition of the results obtained by two electrochemical methods - electrochemical impedance spectroscopy (EIS) and the method of the polarization resistance [20].

Table 1. Data referring to the quaternary ammonium salt investigated.

\begin{tabular}{cccc}
\hline Compound & Structural formulae & Abbreviation Molar mass \\
3-Methyl-2-phenylbenzo $[d]$ thiazol-3-ium \\
bromide
\end{tabular}

\section{Experimental}

The mild steel used in the present investigation had the following chemical composition (wt \%): $0.16 \mathrm{C}, 0.35 \mathrm{Mn}, 0.01 \mathrm{P}, 0.016 \mathrm{Si}, 0.029 \mathrm{~S}, 0.06 \mathrm{Cr}, 0.10 \mathrm{Cu}$, and balance Fe.

The experiments were carried out using a standard electrochemical three-electrode cell. A mild steel cylinder pressed into a Teflon holder acted as a working electrode (WE). Its surface area of $0.5 \mathrm{~cm}^{2}$ remained precisely fixed. A saturated calomel electrode (SCE) connected through a salt bridge was used as a reference electrode, while a large area platinum leaf was used as a counter electrode.

Prior to each experiment the WE was wet abraded with 600 grade emery paper, rinsed with distilled water and an ethanol-ether mixture and then inserted immediately into the glass cell that contained $250 \mathrm{~mL}$ of the electrolyte solution. It was found that $1 \mathrm{~h}$ exposure time to the solution was adequate in case of high temperatures. The same exposure time was used prior to the application of the polarisation resistance method. 
EG\&G Instruments electronic equipment was used. It included a PAR Model 273 Potentiostat and a 5208 Two Phase Lock-in Analyzer which enabled impedance measurements in the $0.1 \mathrm{mHz}-100 \mathrm{kHz}$ range. Two programmes, M378 and PARCalc M342 were used for collecting and evaluating the experimental data.

The response of the electrochemical system to AC excitation with a frequency ranging from $95 \mathrm{kHz}$ to $0.1 \mathrm{~Hz}$ and peak to peak AC amplitude of $5 \mathrm{mV}$ was followed. The lock-in amplifier technique was used for frequencies varying from $5 \mathrm{~Hz}$ to $95 \mathrm{kHz}$ with 5 points per decade. Measurements below $10 \mathrm{~Hz}$ were carried out using the fast Fourier transform (FFT) technique with 8 data cycles. All EIS spectra were recorded at the open-circuit potential (OCP). The latter was measured and then held potentiostatically. Various equivalent circuit models were fitted to the impedance data using a non-linear optimization programme.

The WE was polarized at about $\pm 15 \mathrm{mV} v s . E_{\text {corr }}$ at a scan rate of $0.1 \mathrm{mV} \mathrm{s}^{-1}$ when the polarisation resistance method $\left(R_{\mathrm{p}}^{\mathrm{DC}}\right)$ was applied. PARCalc 342 data analysis technique was used. The Stern-Geary kinetics equation was is applied to determine the best-fit value of $E_{\text {corr }}$ and $R_{\mathrm{p}}$. The experiments were conducted thermostatically at $30^{\circ} \mathrm{C}$, $40^{\circ} \mathrm{C}, 50^{\circ} \mathrm{C}$ and $60^{\circ} \mathrm{C}$. All values presented were calculated as the average of five independent measurements. The corresponding standard deviation was reported as well.

The total surface of the samples was attacked by corrosion and as no local corrosion was experimentally observed, the average inhibitor efficiency was estimated using the formulae given below.

The protective effect, $Z(\%)$, and the coefficient of protection, $\gamma$, were calculated on the basis of the data from the electrochemical experiments with the application of:

$$
Z(\%)=\frac{R_{\mathrm{ct}}^{\mathrm{inh}}-R_{\mathrm{ct}}^{0}}{R_{\mathrm{ct}}^{\mathrm{inh}}}
$$

The value of the coefficient of protection, $\gamma$, was estimated on the ground of:

$$
\gamma=\frac{R_{\mathrm{ct}, \mathrm{corr}}^{0}}{R_{\mathrm{ct}, \mathrm{corr}}^{\text {inh }}}
$$

where $R_{\mathrm{ct}}^{0}$ and $R_{\mathrm{ct}}^{\mathrm{inh}}$ were the polarisation resistance in the inhibitor's absence and presence, respectively.

\section{Results and discussion}

The EIS measurements were carried out in the temperature range of $30-60^{\circ} \mathrm{C}$ under the conditions of active self-dissolution, i.e. at open circuit corrosion potential in presence and absence of inhibitor. The quaternary ammonium salt was studied at its optimal concentration of $1 \times 10^{-4} \mathrm{~mol} / \mathrm{l}$. This value refers to the plateau region of the concentration dependence of the inhibiting effect (studied under gravimetrical method conditions [18]). 
The impedance spectrum in the complex plain $\left(Z^{\prime}-Z^{\prime \prime}\right)$ is a single semicircle at all temperature values studied. This is valid for the experiments carried out not only in presence but also in absence of the inhibitor studied. This is expressed in the Bode plot by the characteristic change of the phase angle $\varphi$ and the slope of $\log |Z| v s$. the frequency applied indicating the presence of a single time constant. This is illustrated in Figures 1 and 2 in presence of inhibitor and in Figure 3 - in $1 \mathrm{M} \mathrm{HCl}$ without inhibitor.
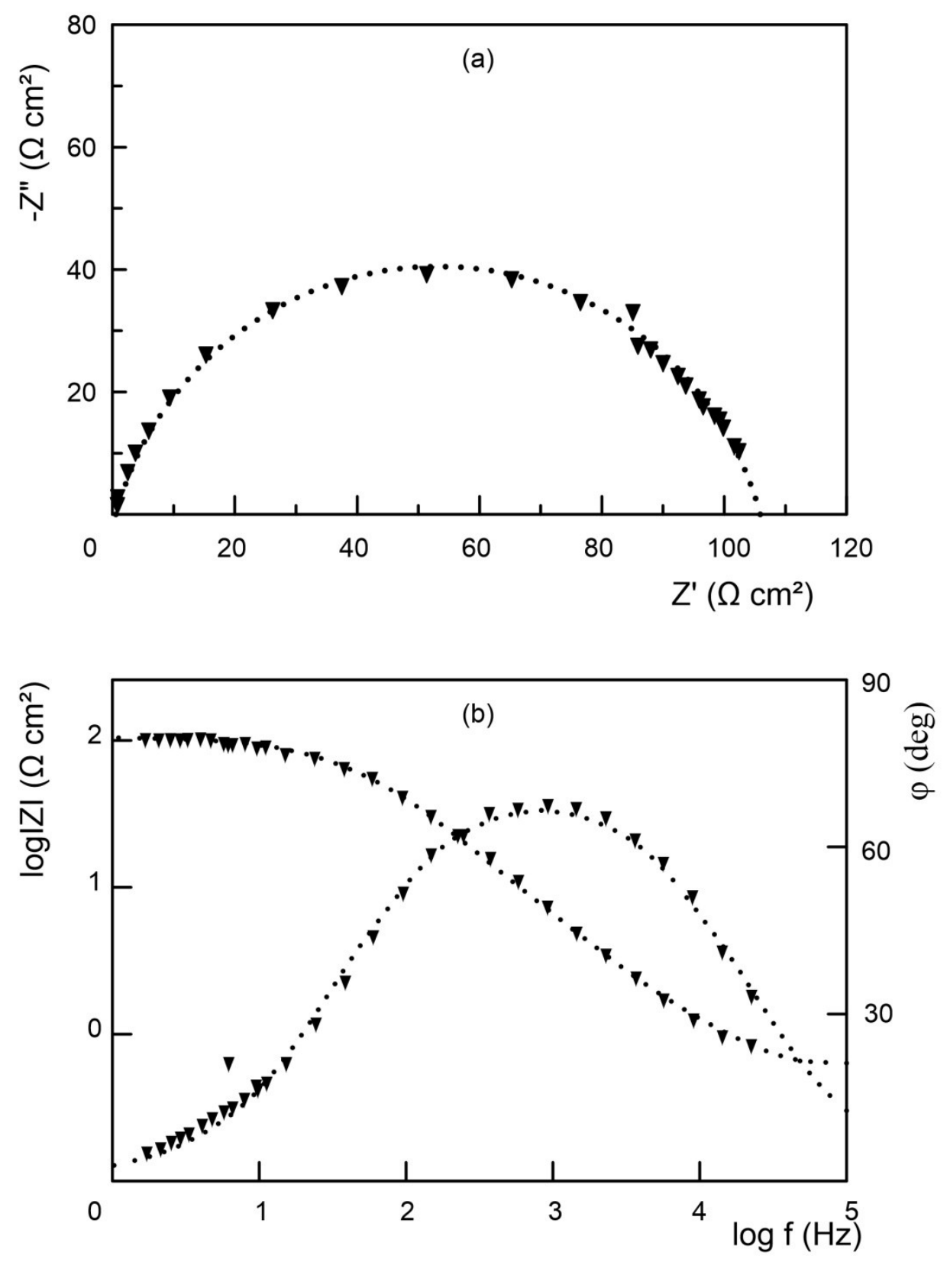

Figure 1. Impedance diagrams at $40^{\circ} \mathrm{C}$ in presence of $10^{-4} \mathrm{M}$ MPTB: $(a)$ Nyquist plot; $(b)$ Bode plot: $\boldsymbol{\nabla}$ - experimental data; $\cdots$ - calculated values. 

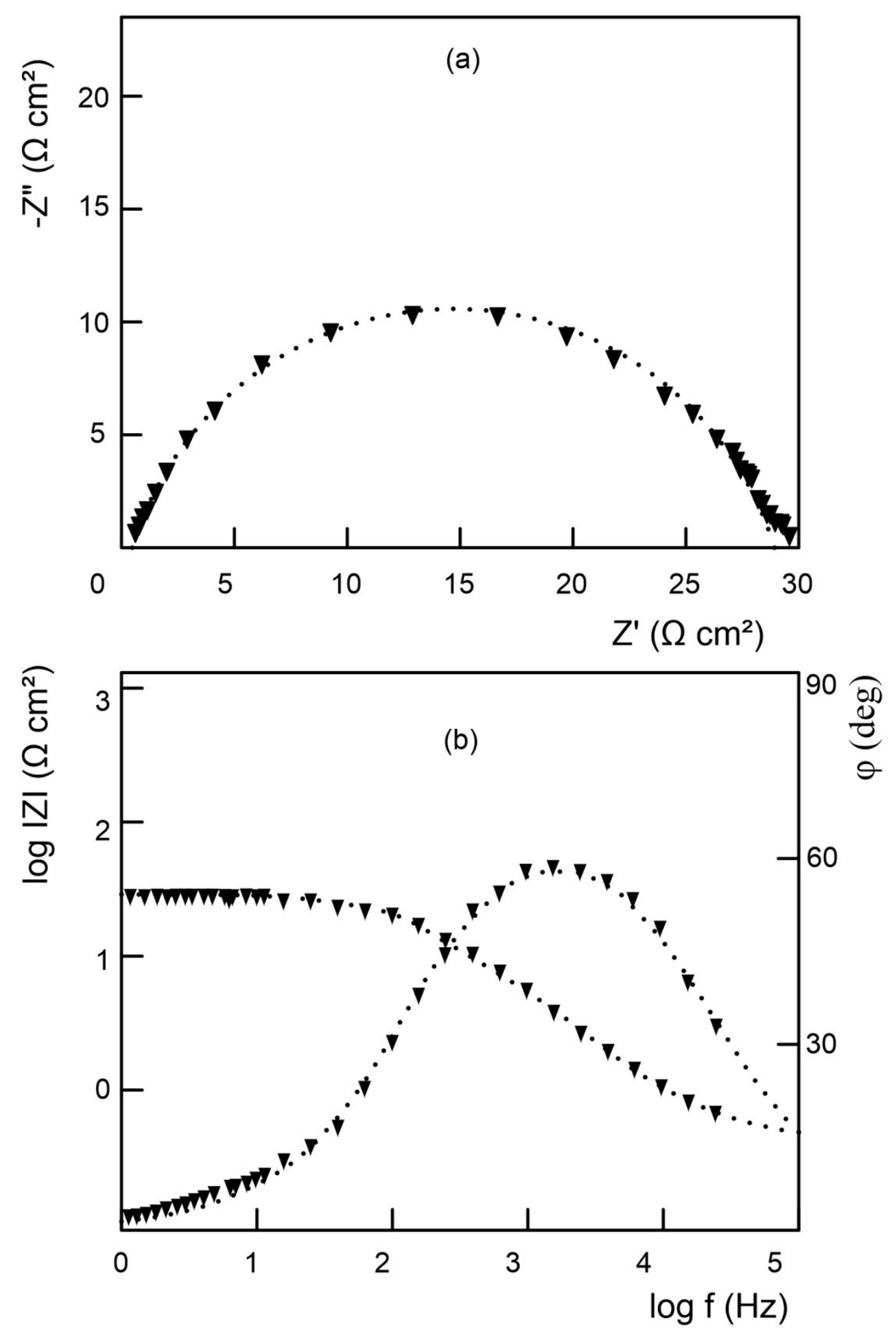

Figure 2. Impedance diagrams at $60^{\circ} \mathrm{C}$ in presence of $10^{-4} \mathrm{M}$ MPTB: $(a)$ Nyquist plot; $(b)$ Bode plot: $\boldsymbol{\nabla}$ - experimental data; $\cdots$ - calculated values. 

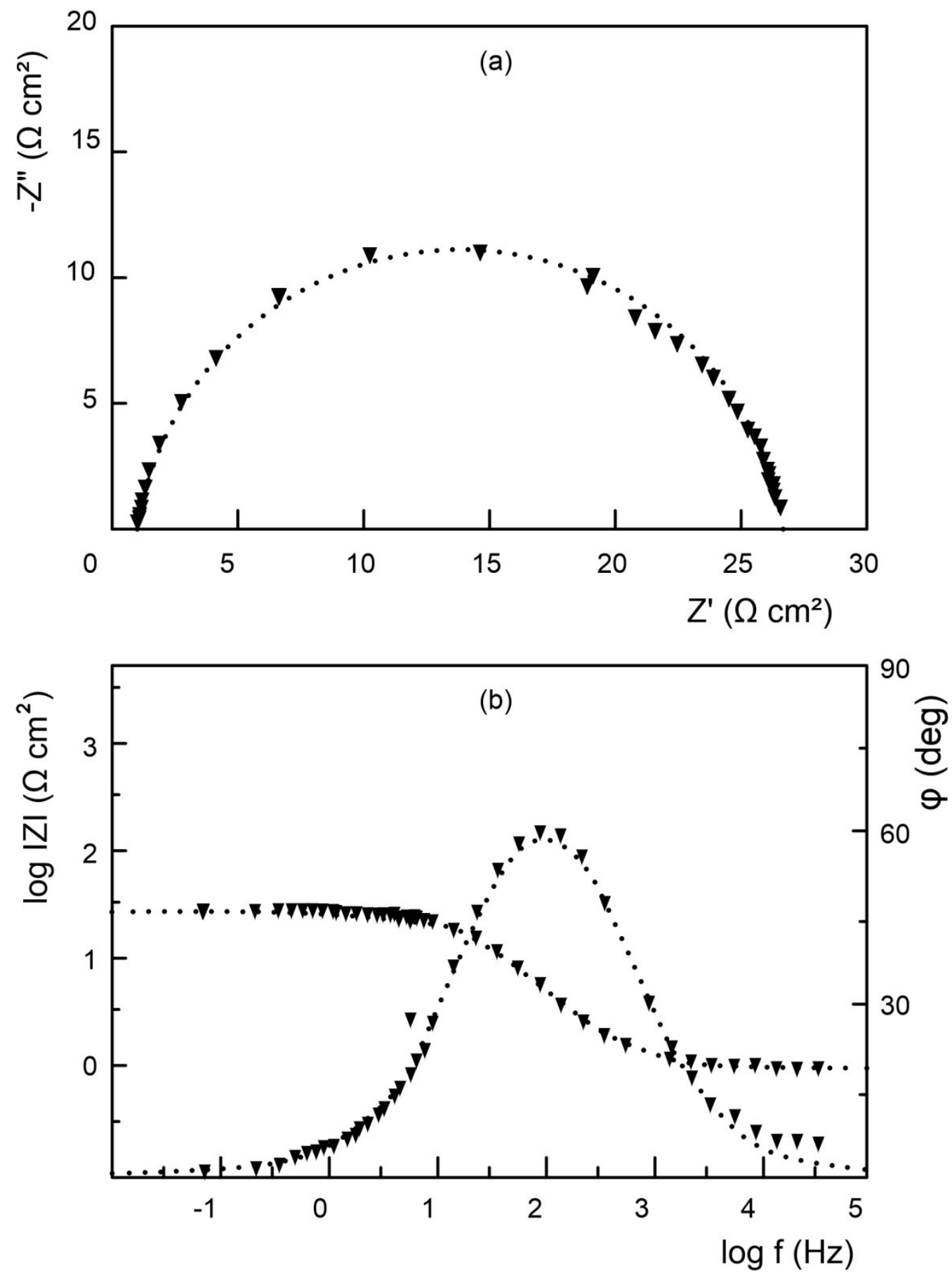

Figure 3. Impedance diagrams at $30^{\circ} \mathrm{C}$ in $1 \mathrm{M} \mathrm{HCl}$ : (a) Nyquist plot; (b) Bode plot: $\boldsymbol{\nabla}$ experimental data; $\cdots$ - calculated values. 
Different theoretical transfer functions, $Z(\omega)$, were used for the quantitative analysis of the experimental results. The function

$$
Z(\omega)=R_{2}+\frac{1}{1 / R_{1}+i \omega C}
$$

was found the most adequate. It is presented by the structural model shown in Figure 4.

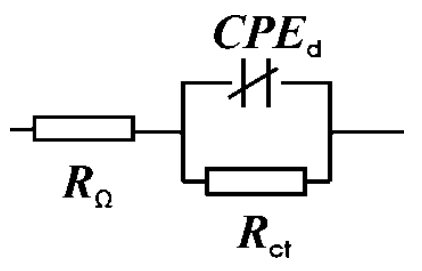

Figure 4. A structural model of the interface (a single time constant).

The resistance $R_{2}$ is identified by the ohmic resistance $R_{\omega}$, which represents the resistance of the metal conductors and that of the electrolyte. $C$ is the double layer capacitance, while $R_{1}$ is the charge transfer resistance $R_{\mathrm{ct}}$. The model illustrated indicates that the Faraday impedance represents the electrochemical reaction proceeding. But the experimental results show that the center of the capacitance semicircle lies under the abscissa which is attributed to the presence of a frequency distributed parameter. That is why the pure capacitance $\mathrm{C}$ is substituted by a Constant Phase Element (CPE), i.e. a model element of frequency distributed behavior is introduced to the structural model illustrated in Figure 4. CPE summarizes the impedance answer of the distribution process in a single expression [21-23] and is given by:

$$
Z_{\mathrm{CPE}}=A^{-1}(i \omega)^{-n} \text {, }
$$

where $A$ is a coefficient of proportionality, $\omega$ is frequency in $\operatorname{rad~s}^{-1}, i=\sqrt{-1}$, while $n$ has the meaning of a phase shift (CPE has pure capacitance behavior in case $n=1$ ). The dispersion of the capacitance semicircle is usually connected with surface inhomogeneity, active centers distribution, inhibitor adsorption, formation of porous layers, etc. [21-25]. That is why it is used as a measure of the surface inhomogeneity. The values of CPE parameters, A and n provide the approximate estimation of the double layer capacitance $C$ [26]:

$$
C=\sqrt[n]{\frac{A}{R^{n-1}}}
$$

The impedance diagram shown above includes a single time constant, $\tau$, which is connected with the time of relaxation of the double layer. This refers to the both systems, i.e. those characterized by inhibitor's presence and absence. The value of the time constant is calculated $[26,27]$ in accordance with: 


$$
\tau=C R
$$

The values of the electrochemical parameters found on the ground of the interface model advanced are summarized in Tables 2 and 3. They are referred to the impedance data. This is illustrated in Figures 1-3.

Table 2. Data referring to the mild steel $/ 1 \mathrm{M} \mathrm{HCl}+1 \times 10^{-4} \mathrm{M}$ MPTB interface.

\begin{tabular}{ccccc}
\hline Temperature $\left({ }^{\circ} \mathbf{C}\right)$ & $\mathbf{3 0}$ & $\mathbf{4 0}$ & $\mathbf{5 0}$ & $\mathbf{6 0}$ \\
\hline$R_{\mathrm{ct}}\left(\Omega \mathrm{cm}^{2}\right)$ & $168.0 \pm 6.2$ & $98.5 \pm 7.4$ & $48.2 \pm 1.6$ & $28.6 \pm 0.8$ \\
$A_{\mathrm{d}}\left(\mathrm{s}^{-n} \Omega \mathrm{cm}^{2}\right)$ & $10976 \pm 1873$ & $8945 \pm 1057$ & $7437 \pm 941$ & $5813 \pm 952$ \\
$10^{6} A_{\mathrm{d}}^{-1}\left(\mathrm{~s}^{n} \Omega^{-1} \mathrm{~cm}^{-2}\right)$ & 91 & 112 & 134 & 172 \\
$10^{6} C_{\mathrm{d}}\left(\mathrm{s} \Omega^{-1} \mathrm{~cm}^{-2}=\mathrm{F} \mathrm{cm}{ }^{-2}\right)$ & 44 & 44 & 48 & 49 \\
$n_{\mathrm{d}}$ & $0.85 \pm 0.01$ & $0.83 \pm 0.01$ & $0.82 \pm 0.01$ & $0.81 \pm 0.01$ \\
$R_{\Omega}\left(\Omega \mathrm{cm}^{2}\right)$ & 0.4 & 0.4 & 0.5 & 0.4 \\
$\tau_{\mathrm{d}}(\mathrm{s})$ & 0.0073 & 0.0041 & 0.0024 & 0.0014 \\
$R_{\mathrm{p}}^{\mathrm{DC}}\left(\Omega \mathrm{cm}^{2}\right)$ & $165.0 \pm 3.2$ & $96.2 \pm 8.3$ & $48.7 \pm 2.3$ & $31.1 \pm 3.6$ \\
\hline
\end{tabular}

Table 3. Data referring to the mild steel / $1 \mathrm{M} \mathrm{HCl}$ interface.

\begin{tabular}{ccccc}
\hline Temperature $\left({ }^{\circ} \mathbf{C}\right)$ & $\mathbf{3 0}$ & $\mathbf{4 0}$ & $\mathbf{5 0}$ & $\mathbf{6 0}$ \\
\hline$R_{\mathrm{ct}}\left(\Omega \mathrm{cm}^{2}\right)$ & $30.1 \pm 5.2$ & $17.4 \pm 0.4$ & $8.0 \pm 2.6$ & $2.8 \pm 0.3$ \\
$A_{\mathrm{d}}\left(\mathrm{s}^{-n} \Omega \mathrm{cm}^{2}\right)$ & $1406 \pm 160$ & $1105 \pm 92$ & $612 \pm 54$ & $275 \pm 15$ \\
$10^{4} A_{\mathrm{d}}^{-1}\left(\mathrm{~s}^{n} \Omega^{-1} \mathrm{~cm}^{-2}\right)$ & 7.11 & 9.05 & 16.34 & 36.36 \\
$10^{4} C_{\mathrm{d}}\left(\mathrm{s} \Omega^{-1} \mathrm{~cm}^{-2}=\mathrm{F} \mathrm{cm}^{-2}\right)$ & 22.7 & 29.8 & 55.3 & 111.8 \\
$n_{\mathrm{d}}$ & $0.84 \pm 0.01$ & $0.83 \pm 0.01$ & $0.81 \pm 0.01$ & $0.80 \pm 0.01$ \\
$R_{\Omega}\left(\Omega \mathrm{cm}^{2}\right)$ & 1.0 & 0.7 & 0.7 & 0.4 \\
$\tau_{\mathrm{d}}(\mathrm{s})$ & 0.0683 & 0.0518 & 0.0442 & 0.0313 \\
$R_{\mathrm{p}}^{\mathrm{DC}}\left(\Omega \mathrm{cm}^{2}\right)$ & $30.2 \pm 3.2$ & $17.5 \pm 0.3$ & $8.3 \pm 2.0$ & $3.1 \pm 0.9$ \\
\hline
\end{tabular}

It is seen that the temperature increase brings about decrease of the charge transfer resistance $R_{\mathrm{ct}}$ both in inhibitor's presence and absence. The same dependence is observed in case of $R_{\mathrm{p}}^{\mathrm{DC}}$ whose value is found with the application of a direct current method - the polarization resistance method. It is worth noting that the values $\left(R_{\mathrm{ct}}\right.$ and $\left.R_{\mathrm{p}}^{\mathrm{DC}}\right)$ estimated on the ground of both methods coincide well. In fact this verifies that the corrosion rate increases. 
The juxtaposition of $R_{\mathrm{ct}}$ and $R_{\mathrm{p}}^{\mathrm{DC}}$ values, correspondingly, in presence and absence of MPTB shows that the protective properties are determined by the inhibitor's adsorption on the metal surface at each of the temperatures studied. They decrease with temperature increase both in inhibitor's presence and absence. As expected the self-dissolution of the metal in pure $1 \mathrm{M} \mathrm{HCl}$ proceeds with a much greater rate when compared to that in the inhibitor's presence. The values of the protective effect, $Z(\%)$, and the coefficient of protection, $\gamma$, are estimated on the ground of the data referring to $R_{\mathrm{ct}}$ and $R_{\mathrm{p}}$ using Eqs. 1 and 2. Their temperature dependences are illustrated in Figure 5 (the data presented was obtained on the ground of $R_{\mathrm{ct}}$ values). It is evident that MPTB provides protection even in case of $1 \times 10^{-4} \mathrm{M}$ presence (the compound's solubility is limited). Furthermore it shows a tendency of intensifying its inhibitive properties with temperature increase.

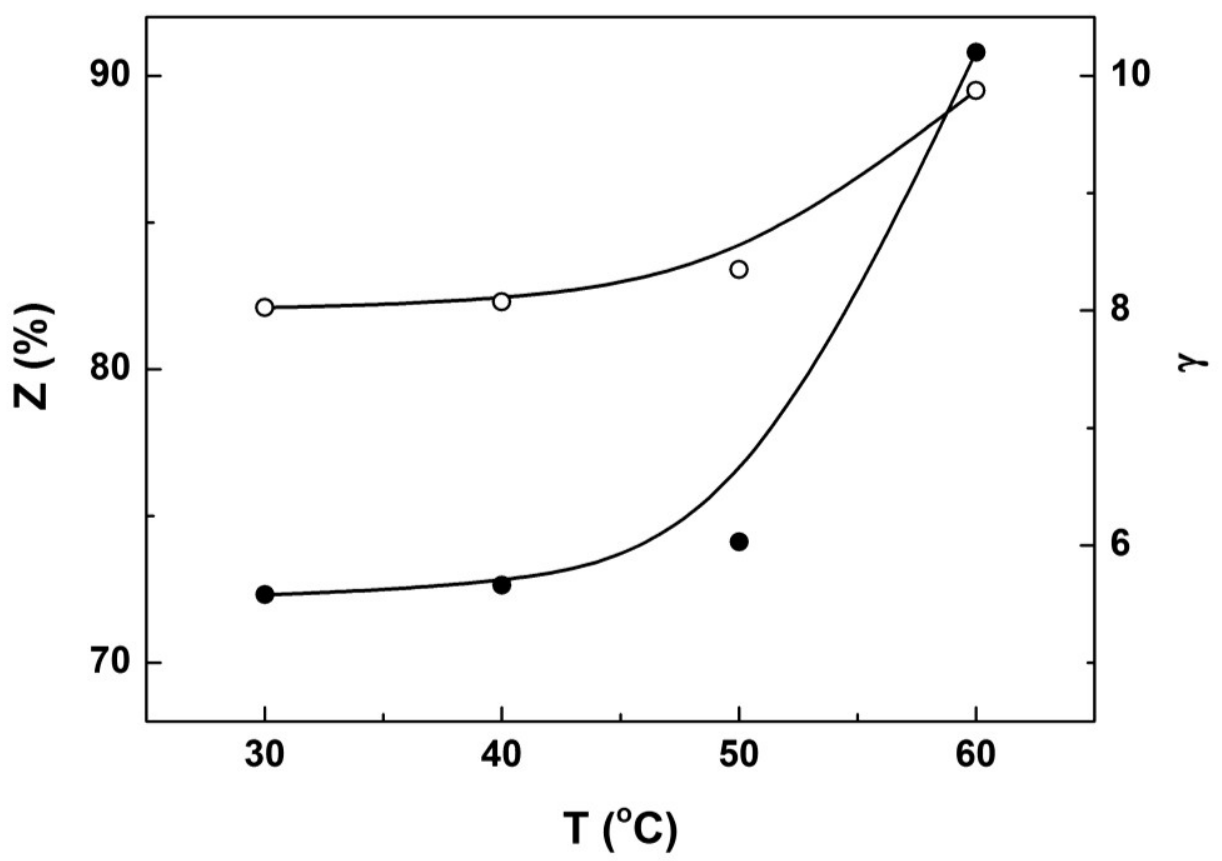

Figure 5. Temperature dependences of the inhibiting effect, $Z(\%)-(0)$ and the extent of protection, $\gamma$ (on the ground of $R_{\mathrm{ct}}$ data) $-(\bullet)$.

The double layer capacitance in presence of MPTB remains almost constant with a slight tendency of an increase with temperature increase in the temperature range investigated. $C_{\mathrm{d}}$ in $1 \mathrm{M} \mathrm{HCl}$ increases with temperature increase having higher values at all temperatures than those of $C_{\mathrm{d}}$ in inhibitor's presence. This can be attributed to the thickness of the adsorption layer which most probably decreases with temperature increase.

It is evident that the value of $n_{\mathrm{d}}$ decreases with temperature increase in presence of MPTB which is indicative of surface inhomogeneity increase. This effect can be attributed on one hand to a certain shift of the adsorption-desorption equilibrium towards desorption, 
while on the other - to roughening of the metal surface as a result of the accelerated corrosion. The same temperature effect on $n_{\mathrm{d}}$ is observed in $1 \mathrm{M} \mathrm{HCl}$ as well. The increased surface inhomogeneity in the latter case can be connected with the roughening of the metal surface brought about by the increased self-dissolution of the metal [23].

The time constant, $\tau$, indicates the time required for the double layer relaxation resulting from the alternating perturbation. Its value decreases with temperature increase both in presence and absence of MPTB. This tendency can be explained with the decrease of the double layer density. It should be added that the relaxation time in inhibitor presence is of an order of magnitude less when compared to that in $1 \mathrm{M} \mathrm{HCl}$. This is indicative of strong adsorption forces between the inhibitor and the metal surface.

It is known that quaternary ammonium salts dissociate in aqueous media giving an ammonium cation and the corresponding anion. In case of MPTB these are the 3-methyl-2phenylbenzo[ $[d]$ thiazol-3-ium cation which has a great area and $\mathrm{Br}^{-}$.

The adsorption layer which is deposited on the metal surface changes the structure of the double layer and hence the kinetics of the electrochemical reactions determining the corrosion process. Alongside with this it isolates partially the surface from the corrosion medium effect. The presence of cations and halogen anions in the corrosion medium brings about synergism according to some authors [1-4, 28, 29].

There are a few hypotheses explaining the beneficial effect of the halogen anions in presence of the inhibitor's cation form. According to one of them the halogen ions hold to the metal surface because of specific adsorption which is not determined by purely electrostatic forces. Their charge attributes to the charge of the metal surface. The metalhalogen dipoles thus emerging on the metal surface shift the zero charge potential in a positive direction which brings about a more negative charge to the surface. This facilitates the electrostatic adsorption of the cations present in the solution [1]. Another hypothesis explains the inhibiting effect with adsorption phenomena. In case of a great extent of surface coverage electrostatic forces of repulsion can appear between the cations in the adsorbed layer. The presence of negative ions ( $\mathrm{Br}^{-}$in this case) decreases the repulsion and provides the tightening of the layer. Hence the metal is better shielded $[1,2]$.The inhibiting properties of MPTB could be explained on the ground of the both effects pointed above as they are valid for quaternary ammonium salts as well. But the slightly positive value of the attraction constant $a$ of the Frumkin's isotherm $(a=0.13)$ found [21] for the substance investigated shows the lack of repulsion in the adsorption layer. Hence it can be concluded that the very good protective properties of MPBT when compared to those of other quaternary ammonium salts are predominantly determined by the proceeding of electrostatic adsorption further facilitated by the structure of its cation part and consequently by its significant area. 


\section{Conclusions}

1. The compound investigated has very good protective properties in case of corrosion of mild steel in $1 \mathrm{M} \mathrm{HCl}$ at relatively high temperature values $\left(30-60^{\circ} \mathrm{C}\right)$. The inhibiting effect increases slightly with temperature increase.

2. The processes at the interface in presence of MPTB in $1 \mathrm{M} \mathrm{HCl}$ are adequately described by the structural model advanced. It contains a single time constant.

3. The protective properties of the compound are due to the electrostatic coulomb adsorption of the cations whose area is relatively high. It is favorably affected by the specific adsorption of bromide anions.

\section{Acknowledgements}

The authors acknowledge for financial support from the National Fund for Scientific Research of Bulgaria (DFNI-T 02/27 and DFNI E 02/11).

\section{References}

1. I. L. Rozenfel'd, Ingibitory korrozii (Corrosion inhibitors), 1977, Moscow, Khimiya, p. 120 (in Russian)

2. L. I. Antropov, E. M. Makushin and V. F. Panasenko, Ingibitory korrozii metallov (Metal Corrosion Inhibitors), Kiev, Tekhnika, 1981, p.182 (in Russian)

3. S. M. Reshetnikov, Ingibitory kislotnoi korrozii metallov (Metal Acid Corrosion Inhibitors), Khimiya, Leningrad, 1986, p. 142 (in Russian)

4. E. S. Ivanov, Ingibtory kislotnoy korrozii metalov (Metal Acid Corrosion Inhibitors), Metallurgiya, Moscow, 1986, p. 173 (in Russian)

5. Ya. G. Avdeev and A. Y. Luchkin, Int. J. Corros. Scale Inhib., 2013, 2, no. 1, 53. doi: 10.17675/2305-6894-2013-2-1-053-066

6. G. Ostapenko, P. Gloukhov and S. Sadivskiy, ECS Transactions, 2009, 19, 47.

7. J. Fu, J. Pan, Z. Liu, S. Li and Y. Wang, Int. J. Electrochem. Sci., 2011, 6, 2072.

8. G. I. Ostapenko, P. A. Gloukhov and S. Ya. Sadivskiy, European Corrosion Congress 2010 - EUROCORR, 2010, 2, p. 1384.

9. M. Yadav, S. Kumar and D. Sharma, Anti-Corros. Meth. Mater., 2014, 61, 129.

10. O. Olivares-Xometl, C. López-Aguilar, P. Herrastí-González, N. V. Likhanova, I. Lijanova, R. Martínez-Palou and J. A. Rivera-Márquez, Ind. Eng. Chem., 2014, 53, 9534.

11. P. Mourya, P. Singh, A. K. Tewari, R. B. Rastogi and M. M. Singh, Corros. Sci., $2015,95,71$.

12. Yu. I. Kuznetsov, Int. J. Corros. Scale Inhib., 2015, 4, no. 1, 15. doi: 10.17675/23056894-2015-4-1-015-034

13. Yu. I. Kuznetsov, Int. J. Corros. Scale Inhib., 2015, 4, no. 4, 284. doi: 10.17675/23056894-2015-4-4-1 
14. X. Zheng, S. Zhang, W. Li, L. Yin, J. He and J. Wu, Corros. Sci., 2014, 80, 383.

15. M. A. Hegazy, A. M. Badawi, S. S. Abd El Rehim and W. M. Kamel, Corros. Sci., 2013, 69, 110.

16. N. Abdulwali, H. Ennajih, R. A. Subari, A. Guenbour, A. Bellaouchou, J. G. Anton and E. M. Essassi, J. Corros. Sci. Eng., 2012, 15 (preprint).

17. A. Nahlé, M. Al-Khayat, I. Abu-Abdoun and I. Abdel-Rahman, Anti-Corros. Meth. Mater., 2013, 60, 20.

18. A. Popova, M. Christov and A. Vasilev, Corros. Sci., 2011, 53, 679.

19. A. Nahle, I. Abu-Abdoun and I. Abdel-Rahman, Int. J. Corros. Scale Inhib., 2015, 4, no. 3, 255. doi: $10.17675 / 2305-6894-2015-4-3-255-268$

20. L. E. Tsygankova, M. N. Esina, V. I. Vigdorovich and N. V. Shel, Int. J. Corros. Scale Inhib., 2014, 3, no. 1, 48. doi: 10.17675/2305-6894-2014-3-1-048-058

21. Z. B. Stoynov, B. I. Grafov, B. S. Stoynova and V. V. Ekilik, Elektrokhimicheskii impedans (Electrochemical Impedance), Moscow, Nauka, 1991, p. 276 (in Russian).

22. Z. Stoynov, Electrochim. Acta, 1990, 5, 149.

23. F. B. Growcock and J. H. Jasinski, J. Electrochem. Soc., 1989, 136, 3210.

24. U. Rammelt and G. Reinhard, Corros. Sci., 1987, 27, 373.

25. A. Popova, Corros. Sci., 2007, 49, 2144.

26. H. Ma, X. Cheng, G. Li, S. Chen, Z. Quan, S. Zhao and L. Niu, Corros. Sci., 2000, 42, 1669.

27. S. Toshima and I. Uchida, Electrochim. Acta, 1970, 15, 1717.

28. L. Bai, L. J. Feng, H.-Y. Wang, Y.B. Lu, X.-W. Lei and F.-L.Bai, RSC Adv., 2015, 5, 4716.

29. M. Abouchane, M. El Bakri, R. Touir, A. Rochdi, O. Elkhattabi, M. Ebn Touhami, I. Forssal and B. Mernari, Res. Chem. Intermed., 2015, 41, 1907. 